Physical Disabilities: Education and Related Services, 2016, 35(2), 1-22. doi: 10.14434/pders.v35i2.21765

(C) Division for Physical, Health and Multiple Disabilities

PDERS

ISSN: 2372-451X

http://scholarworks.iu.edu/journals/index.php/pders/index

Article

\title{
A CROSS-SECTIONAL STUDY OF SCHOOL EXPERIENCES OF BOYS WITH DUCHENNE AND BECKER MUSCULAR DYSTROPHY
}

\author{
Aida Soim \\ New York State Department of Health \\ Molly Lamb \\ University of Colorado, Denver \\ Kimberly Campbell \\ New York State Department of Health \\ Shree Pandya \\ University of Rochester \\ Holly Peay \\ RTI International \\ James F. Howard, Jr. \\ The University of North Carolina at Chapel Hill \\ Deborah Fox \\ New York State Department of Health \\ Muscular Dystrophy Surveillance, Tracking, and Research Network (MD STARnet)
}

\begin{abstract}
The objectives of this study were to investigate types of supportive school services received and factors related to provision of these services. We conducted a cross-sectional study to describe the school experience of males with Duchenne and Becker muscular dystrophies. Study subjects were identified through the Muscular Dystrophy Surveillance, Tracking, and Research Network. Non-ambulatory males with Duchenne muscular dystrophy (DMD) were significantly more likely to use an instructional assistant and resource room
\end{abstract}


support when compared to ambulant males with DMD at the time of the caregiver interview. Males with DMD who received occupational therapy were more likely to use an instructional assistant, while those who received speech therapy were more likely to repeat a grade, use an instructional assistant, and receive resource room support. Males with DMD whose primary caregivers had less than 12 years of education were more likely to use an instructional assistant and resource room support. Non-ambulatory males with DMD should continue receiving appropriate school accommodations so they can keep pace with their physical demands. Males with DMD with speech deficits should be considered for various educational interventions.

Keywords: physical impairments; cognitive impairments; speech-language pathology; physical therapy; occupational therapy

\section{Introduction}

Duchenne and Becker muscular dystrophies (DBMD) are genetic conditions that occur almost exclusively in males and are characterized by progressive muscle weakness and atrophy. In 2010, prevalence of DBMD was estimated at 1.38 per 10,000 males, ages 5 to 24 years (Romitti et al., 2015). The two conditions have similar signs and symptoms; however, they differ in age of onset, rate of progression, and severity.

In boys with Duchenne muscular dystrophy (DMD), signs and symptoms are observed between ages 2 and 5 and worsen rapidly (Ciafaloni, Chinnery, \& Griggs, 2014). Males with DMD experience a progressive loss of muscle function resulting in a number of physical challenges such as a decline in mobility with eventual need for a wheelchair by age 12, sleep apnea, limitations in performing daily activities, and respiratory and/or cardiac complications, all of which can hinder their ability to learn (Cyrulnik, Fee, De Vivo, Goldstein, \& Hinton, 2007; Kornberg \& Yiu, 2008; Yiu \& Kornberg, 2015; Zebracki \& Drotar, 2008). It has been shown that the distribution of the average intelligence quotient (IQ) among males with DMD is shifted approximately one standard deviation lower than the distribution of the normative population (Worden \& Vignos, 1962). In addition, previous literature has described a specific cognitive profile associated with DMD, with higher rates of poor performance on tests of digit span, verbal comprehension, and story memory and comprehension (Hinton, De Vivo, Nereo, Goldstein, \& Stern, 2000; Hinton, De Vivo, Fee, Goldstein, \& Stern, 2004; Wicksell, Kihlgren, Melin, \& EegOlofsson, 2007).

In males with Becker muscular dystrophy (BMD), the skeletal muscle involvement is more mild than with Duchenne, the onset of skeletal muscle weakness occurs and is recognized after age five, and some individuals maintain the ability to walk until adulthood (Ciafaloni et al., 2014). A high incidence of learning difficulties was observed among males with BMD; however, individuals with BMD demonstrated a less homogeneous cognitive phenotype than that seen in individuals with DMD (Young et al., 2007). Currently there is no cure for DBMD, but treatment with corticosteroids, use of pulmonary support, and cardiac medication have changed the natural history of DBMD, and individuals are surviving into their thirties and forties. This has created an 
increased focus on preparing individuals with DBMD for employment, independent living, and participation in society.

To our knowledge, there has been virtually no research done on the educational and school experiences of males with DMD or BMD and it is unknown what types of special education services these individuals receive. In the literature, we only identified two studies that reported results on school attendance among males with DBMD. A study on psychological and practical difficulties among parents of children with DBMD by Magliano et al. (2014) reported a school attendance rate of $94.7 \%$ among boys with DMD and $98.9 \%$ among boys with BMD. Similar estimates on school attendance were reported by Lopez-Hernandez et al. (2014). Another two studies evaluated therapies received by males with DBMD (Pandya, Campbell, Andrews, Meaney, \& Ciafaloni, 2015; Zebracki \& Drotar, 2008). The two studies reported similar prevalence of occupational therapy $(\mathrm{OT})$ and physical therapy (PT) received; however, findings of the study by Zebracky and Drotar (2008) were obtained using a relatively small sample size (43 participants with DMD and 10 participants with BMD), while the estimates in the study by Pandya et al. (2015) were not calculated separately for DMD and BMD. In addition, neither of the two studies differentiated between therapies received at school or at facilities outside of school.

There is a paucity of data on types of supportive school services received by males with DBMD and factors related to provision of these services. Therefore, the objectives of this study were to describe accommodations and services provided and examine education-based factors and caregiver characteristics associated with service provision. More specifically, we evaluated the distribution of study subject and caregiver characteristics separately among males with DMD and BMD by four dependent variables: participation in general education classes, grade repetition, usage of instructional assistant, and usage of resource room support. In addition, using multivariable models, we evaluated the association between ambulatory status, therapy received, household income, and education level of the caregiver and the aforementioned dependent variables among males with DMD.

\section{Method}

\section{Design and Population}

We conducted a cross-sectional study to evaluate the school experiences of males with DBMD using caregiver reports. Individuals with DBMD were identified, both prospectively and retrospectively, beginning in 2004 through the Muscular Dystrophy Surveillance Tracking and Research Network (MD STARnet), a multisite surveillance system for identifying and following individuals with DMD and BMD. The surveillance methodology has been described elsewhere (Miller et al., 2006). Briefly, the MD STARnet cohort included individuals with DBMD born on or after January 1, 1982, in the states of Arizona (AZ), Colorado (CO), Iowa (IA), Georgia (GA), Hawaii (HI), and a 12-county area in western New York state (wNY), who were identified as having a childhood-onset dystrophinopathy and were diagnosed before their $21^{\text {st }}$ birthday through neuromuscular clinics, hospitals and hospital discharge databases, private physicians, service sites for children with special care needs, and birth defects surveillance programs. 
Our study population included males with definite and probable DBMD diagnosis (Mathews et al., 2010). A male with documented clinical symptoms referable to a childhood-onset dystrophinopathy was categorized as definite if he met one or more of the following criteria: a positive genetic test for dystrophin mutation; a muscle biopsy demonstrating abnormal dystrophin; or an elevated creatine kinase (CK), family history of an X-linked dystrophinopathy, and an affected family member with a positive muscle biopsy or a dystrophin mutation. A male with documented clinical symptoms referable to a dystrophinopathy, elevated CK, and a family history of $\mathrm{X}$-linked dystrophinopathy but no confirmatory genetic testing was categorized as probable.

Figure 1 shows the exclusion criteria used for this study. Excluded were (a) males younger than five years of age at the time of the interview $(n=21)$, (b) residents of Hawaii $(n=2)$ due to restricted ascertainment of individuals with DBMD, (c) males who were not enrolled in school from kindergarten through 12 th grade $(n=31$ deceased at the time of interview, $n=13$ alive at the time of interview and younger than 18 years, and $n=80$ alive at the time of the interview and 18 years old or older), (d) males who were homeschooled $(n=2)$, and (e) males who took postsecondary classes $(n=4)$.

\section{Data Sources and Data Collection}

Data collection consisted of abstraction of medical records, as well as annual follow-up abstraction until December 2011, the time of index male's death, or the time the index male moved outside of a site or catchment area. Abstracted data included demographic and diagnostic information, medical history, and family history of muscular dystrophy for the index males with DBMD. Surveillance data were supplemented with data collected through structured computerassisted telephone interviews of eligible primary caregivers (primary caregivers of MD STARnet males with definite or probable DBMD diagnosis).

Survey sample. The survey was administered to 364 primary caregivers of 402 males with definite or probable diagnosis of DBMD (living or deceased). In the case of families with multiple affected males, we selected a priori to analyze the oldest sibling, in order to meet the statistical assumption of the independence of the observations. The interviews were conducted in two cycles from April 2007 to May 2008 and from April 2009 to March 2012. The cycles corresponded to annual pooling and continued identification of new cases. The dissemination methods were the same across cycles.

The 686 eligible primary caregivers were initially contacted by mail (GA, IA, and wNY), telephone (CO), through the primary health care provider (AZ), or in person (HI). Any differences in methods used to contact the caregivers were due to differences in site institutional review board requirements. An introductory packet was provided to the primary caregiver and contained a letter that described the study in detail, a project brochure, information on the rights of research subjects, and frequently asked questions, along with $\$ 20$ compensation. The telephone interviews took between 45 and 60 minutes, were conducted in English or Spanish, and collected information about socio-demographic characteristics of the primary caregivers such as education level and household income, residence history, social support, medical and 
assistive technology services received, and information about schooling of the males with DBMD. Follow-up was done using a systematic protocol to obtain consent to conduct the interviews.

The response, cooperation, and refusal rates, calculated using the American Association for Public Opinion Research (AAPOR) calculator, were 53\%, 66\%, and 28\%, respectively (Response Rates - An Overview - AAPOR, n.d.). Response rate was the number of primary caregivers who answered the survey divided by the number of eligible primary caregivers in the sample. The cooperation rate was the proportion of all primary caregivers interviewed to all eligible primary caregivers ever contacted, where contact was verified. It included partial interviews as respondents. The refusal rate was the proportion of all primary caregivers who refused to be interviewed, or who broke off an interview, to all potential primary caregivers. The procedures for data collection were approved by the institutional review board at each site.

Because DMD and BMD differ in their severity and rate of progression, we conducted separate analyses for each of these conditions. To include males with intermediate DMD and take into account the effect of corticosteroid treatment on prolonged ambulation, we categorized males who lost ambulation before 16 years of age as DMD and males who lost ambulation at or after $16^{\text {th }}$ birthday as BMD. If ambulation status was not available at the time of the interview, or the child was too young to determine the type of dystrophinopathy based on ambulation status, age at first signs and symptoms was used to separate Duchenne from Becker (first signs and symptoms before age six years for DMD and after age of six years for BMD). We could not classify one male due to missing information on age at onset of first signs and symptoms. The final analytic sample consisted of 210 males with DBMD who were categorized as DMD $(n=$ $179)$ and $\operatorname{BMD}(n=31)$ (see Figure 1).

\section{Variables}

We evaluated the following independent variables: enrolled in general education classes (yes/no), grade repetition (yes/no), used instructional assistant (yes/no), and used resource room support (yes/no). A student who is enrolled in school but does not attend general education classes may attend school in the same building as other students, but is in a separate classroom all day. Grade repetition occurs when a child does not make academic progress or is not socially or emotionally moving ahead with his same-age peers. An instructional assistant's role in a general education classroom is to support a student to access the curriculum. A resource room is a classroom where an adapted educational curriculum is delivered to a student with a disability.

We selected these outcomes because, given enough resources, they can be improved (e.g. males with DMD may receive more instructional assistance and resource room support to meet the education requirements thereby reducing the need for grade repetition). Instructional assistant usage and resource room support are both examples of accommodations that improve access to the curriculum for students with special needs. The abstractors did not have access to the school records, so the survey was used to obtain information on school experiences and school needs for males with DBMD. The responses to these questions were used to derive our dependent variables and for exclusion criteria. 


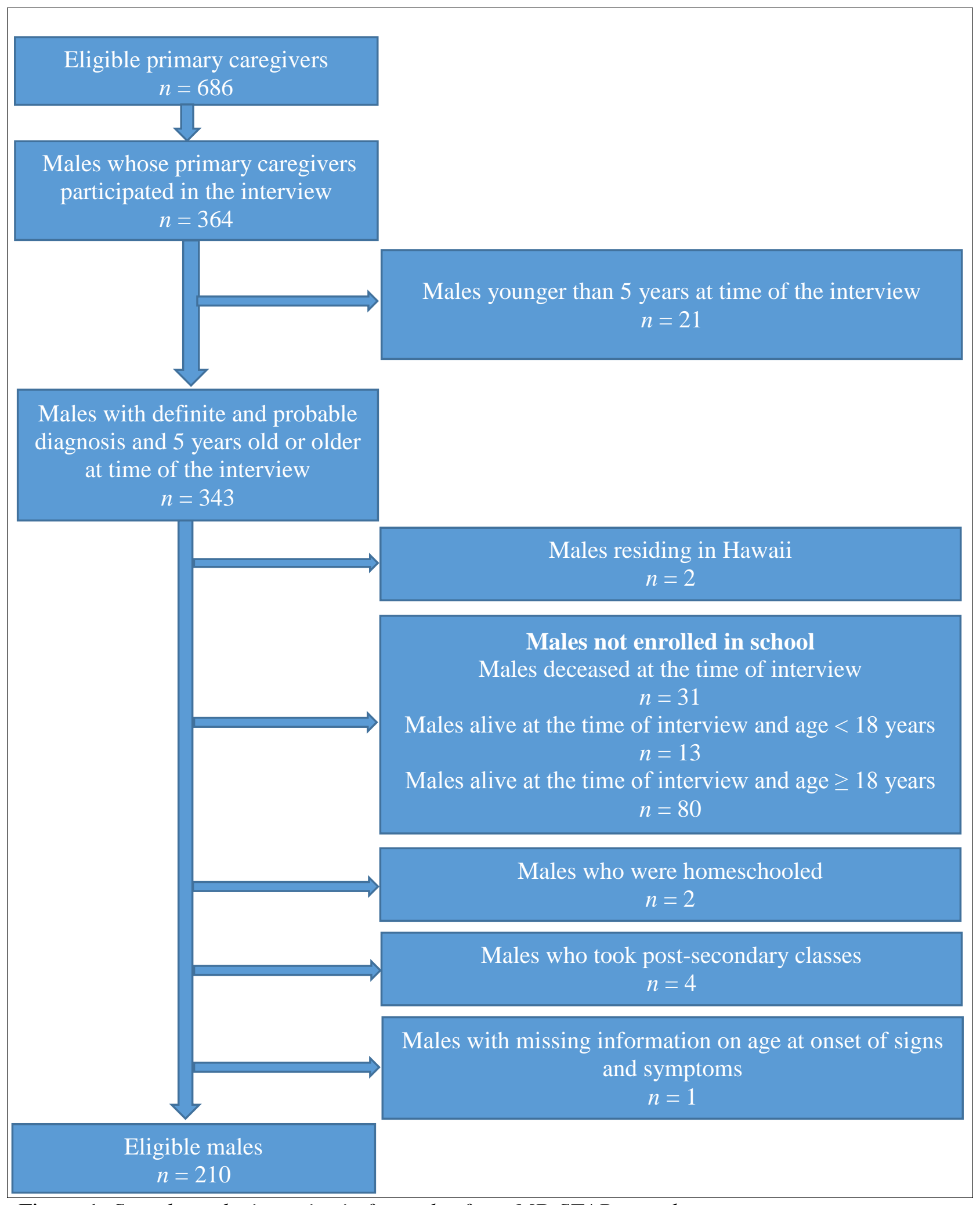

Figure 1. Sample exclusion criteria for males from MD STARnet cohort 
The following factors were examined as independent variables: (a) age of male at the time of interview (5-10 years, 11-14 years, and $\geq 15$ years), (b) race/ethnicity (White non-Hispanic, Black non-Hispanic, Hispanic, and Other race/ethnicity), (c) state of residence, (d) ambulation status (ambulatory, non-ambulatory, and not known), (e) types (occupational, physical, and speech) and location (only at school, school and medical practice or home, only at medical practice or home, and not received) of therapy received, (f) primary caregiver education level ( $\leq$ 12 years, $>12$ years $)$, and $(\mathrm{g})$ annual household income $(<\$ 30,000, \$ 30,000-\$ 50,000$, and $>\$ 50,000)$. The main goals of PT are to improve mobility, to strengthen the large muscle groups, to assist in increasing joint flexibility, and to prevent contractures and scoliosis. OT is focused on the development of fine motor skills that help with accomplishing activities of daily living such as using a computer or dressing. Speech therapy (ST) is recommended for a child with delayed or disordered language and/or articulation skills. We evaluated the ambulatory status and the types of therapies received because they are indicative of the severity of the condition. In addition, we were interested in whether the socio-economic status (SES) of the caregiver was associated with the school experience of boys with DMD and used caregiver education and household income as surrogates for SES.

\section{Statistical Analyses}

Descriptive statistics (frequency counts and percentages) were calculated for all independent variables. For males with DMD, crude prevalence ratio (PR) estimates were calculated for evaluating the associations between study subject and caregiver characteristics, and the outcomes. Because the outcomes did not meet the rare event assumption of a prevalence, $(<10 \%)$, Poisson regression models with a robust error variance were conducted to estimate adjusted prevalence ratios (aPR) and 95\% confidence intervals (Petersen \& Deddens, 2008). All multivariable regression models were adjusted for male's age at interview, race/ethnicity, and state of residence. When evaluating the association between household income and the dependent variables, we adjusted for the number of family members supported by the household income along with other confounders. For each type of therapy received, due to small counts in some categories, we created two groups: therapy received and not received. Lastly, we compared the study subject and caregiver characteristics between males with DBMD who were reported as not attending general education classes to males with DBMD reported as attending general education classes. This sub-analysis was conducted to evaluate how comparable this population was to males who attended general education classes, and to evaluate potential characteristics that may explain the differences between these two samples, and, as a result, the potential selection bias. Data management and analyses were conducted using SAS 9.3 software.

\section{Results}

\section{Descriptive Statistics}

Among the 179 males with DMD, $73.2 \%$ were between five and 15 years of age, $69.8 \%$ were White non-Hispanic, and $58.1 \%$ were non-ambulatory (Table 1). Fifty-four percent were reported as receiving OT in school, $49.2 \%$ received PT, and $49.8 \%$ received ST. Ninety percent of males were reported as attending general education classes while grade repetition was 
reported for $26.3 \%$ of subjects with DMD. Use of an instructional assistant was reported for $59.2 \%$ and use of a resource room was reported for $58.7 \%$ (Table 1). With respect to subjects' primary caregivers, $69.3 \%$ reported having more than 12 years of education and $49.7 \%$ reported an annual income of $>\$ 50,000$. Among the 31 males with BMD, over $71 \%$ were age 11 years and older, $61.3 \%$ were White non-Hispanic, and $67.7 \%$ were ambulatory at the time of the interview (Table 1). About 32.2\% received OT in school, $48.4 \%$ received PT, and $29.0 \%$ received ST. Among primary caregivers of males with BMD, 54.8\% reported more than 12 years of education and $67.7 \%$ reported an annual income $>\$ 50,0000$ (Table 1 ).

Table 1

Distribution of study subject and primary caregiver characteristics in the MD STARnet cohort

\begin{tabular}{|c|c|c|c|c|}
\hline \multirow{2}{*}{$\begin{array}{l}\text { Study Subject } \\
\text { Characteristics } \\
\text { Age groups }\end{array}$} & \multicolumn{2}{|c|}{ DMD $(n=179)$} & \multicolumn{2}{|c|}{ BMD $(n=31)$} \\
\hline & $n$ & $\%$ & $n$ & $\%$ \\
\hline 5-10 years & 71 & 39.7 & 9 & 29.0 \\
\hline $11-14$ years & 60 & 33.5 & 11 & 35.5 \\
\hline$\geq 15$ years & 48 & 26.8 & 11 & 35.5 \\
\hline \multicolumn{5}{|l|}{ Race/ethnicity } \\
\hline White non-Hispanic & 125 & 69.8 & 19 & 61.3 \\
\hline Black non-Hispanic & 9 & 5.0 & 3 & 9.7 \\
\hline Hispanic & 28 & 15.6 & 6 & 19.4 \\
\hline Other & 7 & 3.9 & 0 & \\
\hline Unknown & 10 & 5.6 & 3 & 9.7 \\
\hline \multicolumn{5}{|l|}{ State } \\
\hline $\mathrm{AZ}$ & 43 & 24.0 & 5 & 16.1 \\
\hline $\mathrm{CO}$ & 34 & 19.0 & 5 & 16.1 \\
\hline GA & 40 & 22.4 & 7 & 22.6 \\
\hline IA & 32 & 17.9 & 8 & 25.8 \\
\hline western NY & 30 & 16.8 & 6 & 19.4 \\
\hline \multicolumn{5}{|l|}{ Ambulation status } \\
\hline Ambulatory & 58 & 32.4 & 21 & 67.7 \\
\hline Non-ambulatory & 104 & 58.1 & 6 & 19.4 \\
\hline Don't know & 17 & 9.5 & 4 & 12.9 \\
\hline \multicolumn{5}{|l|}{ Occupational therapy } \\
\hline Only at school & 74 & 41.3 & 9 & 29.0 \\
\hline School and MP/Home & 23 & 12.9 & 1 & 3.2 \\
\hline Only at MP/Home & 29 & 16.2 & 2 & 6.5 \\
\hline Not received & 50 & 27.9 & 19 & 61.3 \\
\hline Missing & 3 & 1.7 & 0 & \\
\hline \multicolumn{5}{|l|}{ Physical therapy } \\
\hline Only at school & 56 & 31.3 & 10 & 32.3 \\
\hline School and MP/Home & 32 & 17.9 & 5 & 16.1 \\
\hline Only at MP/Home & 69 & 38.6 & 9 & 29.0 \\
\hline
\end{tabular}


Speech therapy

Not received

Missing

Only at school

School and MP/Home

Only at MP/Home

Not received

Missing

General education classes

Participates

Does not participate

Grade repetition

$$
\text { Yes }
$$

No

Missing

Instructional assistant

Yes

No

Missing

Resource room
21

1

78

11

13

75

2

162

17

47

130

2

106

72

1
11.7

0.6

43.6

6.2

7.3

41.9

1.1

90.5

9.5

26.3

72.6

1.1

59.2

40.2

0.6

40.8

0.6 $\begin{array}{lll}105 & 58.7 & 11\end{array}$
7

0

9

0

2

20

0

30

1

96.8

3.2

19.4

80.6

25

0

9

22

0

22.6

29.0

6.5

64.5
20

0
29.0

71.0

35.5

64.5

\section{Caregiver and Household}

Characteristics

\begin{tabular}{|c|c|c|c|c|}
\hline \multicolumn{5}{|l|}{$\begin{array}{l}\text { Education level of } \\
\text { caregiver }\end{array}$} \\
\hline$>12$ years & 124 & 69.3 & 17 & 54.8 \\
\hline$\leq 12$ years & 44 & 24.6 & 11 & 35.5 \\
\hline Missing & 11 & 6.2 & 3 & 9.7 \\
\hline \multicolumn{5}{|l|}{ Household income } \\
\hline$<\$ 30,000$ & 59 & 32.9 & 7 & 22.6 \\
\hline$\$ 30,000-\$ 50,000$ & 24 & 13.4 & 2 & 6.5 \\
\hline$>\$ 50,0000$ & 89 & 49.7 & 21 & 67.7 \\
\hline Missing & 7 & 3.9 & 1 & 3.2 \\
\hline
\end{tabular}

MD STARnet $=$ Muscular Dystrophy Surveillance Tracking and Research Network; DMD = Duchene muscular dystrophy; $\mathrm{BMD}=$ Becker muscular dystrophy; $\mathrm{MP}=$ medical practice; $\mathrm{AZ}=$ Arizona; $\mathrm{CO}=$ Colorado; $\mathrm{GA}=$ Georgia; IA = Iowa; NY = western New York State 


\section{Crude Analysis}

Participation in general education classes. Among males with DMD, residing in CO was significantly associated with participating in general education classes (Table 2). No other statistically significant estimates were observed.

Grade repetition. Of the 47 males with DMD who were reported as repeating a grade, $91.5 \%$ repeated a grade in elementary school, $4.2 \%$ repeated a grade in junior high school, and $2.1 \%$ repeated a grade in senior high school. The likelihood of repeating a grade was significantly higher among males with DMD who received ST at school, or at school and medical practice/home compared to males who did not receive any ST. No other significant associations with grade repetition were observed (Table 2).

Instructional assistant usage. Males with DMD 11 years of age and older were more likely to use an instructional assistant (Table 3). These individuals were significantly more likely to use an instructional assistant if they received OT or ST at school, or at school and medical practice/home. Males with DMD who were ambulatory at the time of the interview were significantly less likely to use an instructional assistant compared to those who were nonambulatory (Table 3).

Resource room support. Males with DMD 15 years of age and older were less likely to receive support in a resource room. Subjects who received OT at school and medical practice/home, were 1.69 times as likely to use a resource room as males with DMD who did not receive OT. A $68 \%$ and $92 \%$ increase in the likelihood of using resource room was observed among males with DMD who received ST only at school, or at school and medical practice/home, compared to those who did not receive OT, respectively (Table 3). With respect to education level of the caregiver, the prevalence of resource room use was higher among males whose primary caregivers had less than 12 years of education compared to males whose primary caregiver had at least 12 years of education.

\section{Multivariable Analysis}

Table 4 shows the aPR estimates of multivariable Poisson regression models with robust error variance used to evaluate the associations between ambulation status, therapies, primary caregiver education, household income, and the four dependent variables of interest. Compared to males with DMD who were ambulatory at the time of the interview, those who were not ambulating were $75 \%$ more likely to use an instructional assistant and 54\% more likely to use a resource room. Males with DMD who received OT in school were 1.5 times as likely to use an instructional assistant and $37 \%$ more likely to use resource room support as those who did not receive OT. Significantly elevated aPRs were observed for the association between ST received in school and grade repetition, instructional assistant use, and resource room support. Lastly, males whose primary caregivers had less than 12 years of education were significantly more likely to use an instructional assistant or resource room support compared to males with DMD whose primary caregivers had at least 12 years of education. 
Separately, we evaluated males with DBMD who did not have reported school enrollment at the time of the interview and were excluded from the results above. Out of 124 males who were reported as not being enrolled in school, 31 (25\%) were deceased at the time of the caregiver interview. Out of 93 for whom no participation in general education classes was reported, but were alive at the time of the interview, six $(6.45 \%)$ were homeschooled. Ninety percent were 15 years old or older $(p<0.001)$, their primary caregivers had a lower educational level than those of males who were enrolled in school $(p=0.03)$, and their annual household income was lower than that of males enrolled in school $(p=0.17)$ (Table 5).

\section{Discussion}

We conducted a cross-sectional study to investigate types of supportive school services received by males with DBMD and factors related to provision of these services.

\section{Males with DMD}

The current study observed that, of males with DMD enrolled in school, $90.5 \%$ were reported as participating in general education classes, $26.3 \%$ were reported as repeating a grade, $59.2 \%$ were reported as having an instructional assistant, and $58.7 \%$ were reported as using the resource room. The current study showed that there was no significant difference in participation in general education classes, grade repetition, use of an instructional assistant or resource room among racial/ethnic groups, among residents of different states, and between various levels of household income. Our results suggest that socioeconomic factors do not play a strong role in the educational experience of boys with DMD.

A study by Magliano et al. (2014), conducted in Italy in eight treatment centers for individuals with muscular dystrophies, reported a similar prevalence of males with DMD who attended school (94.7\%) as we observed (90.5\%). Our findings of high levels of participation in general education classes suggest that children with relatively severe physical needs are being integrated into the regular classroom with their age-appropriate peers.

The adjusted analysis showed that non-ambulatory males with DMD had a significantly greater prevalence of using an instructional assistant and resource room support compared to those who were ambulating, suggesting that schools need to plan to allocate greater resources for boys with DMD as they grow older and more physically disabled. Instructional assistant use and resource room support are both examples of accommodations made to improve access to the curriculum for students with special needs. In addition, the Muscular Dystrophy Association (MDA) determined that a variety of classroom accommodations and adaptive equipment, such as adaptive seating to support upright posture, raised desktop or wheelchair tray as desk, adapted keyboards, software and calculators, special pencil grip, and use of tape recorder for note-taking can help males with DMD maximize their physical abilities and excel academically (Heller, Mezei, \& Avant, 2009; Muscular Dystrophy Association, n.d.). To improve classroom access, it is recommended that males with DMD receive preferential seating and are allowed extra time to 
Table 2

Crude prevalence ratio $(P R)$ estimates of the association between study subject and caregiver characteristics and general education classes and grade repetition among DMD cases in the MD STARnet cohort

\begin{tabular}{|c|c|c|c|c|c|c|c|c|c|c|}
\hline \multirow{3}{*}{$\begin{array}{l}\text { Study Subject } \\
\text { Characteristics } \\
\text { Age groups }\end{array}$} & \multicolumn{4}{|c|}{ General Education Classes } & \multirow[t]{3}{*}{ PR (**P value) } & \multicolumn{4}{|c|}{ Repeated Grade } & \multirow[t]{3}{*}{$* \mathbf{P R}(* * \mathbf{P}$ value $)$} \\
\hline & \multicolumn{2}{|c|}{$\begin{array}{c}\text { Participates } \\
(\mathrm{N}=162)\end{array}$} & \multicolumn{2}{|c|}{$\begin{array}{l}\text { Does not } \\
\text { participate } \\
(\mathrm{N}=17)\end{array}$} & & \multicolumn{2}{|c|}{$\begin{array}{c}\text { Repeated } \\
(\mathrm{N}=47)\end{array}$} & \multicolumn{2}{|c|}{$\begin{array}{l}\text { Never repeated } \\
\qquad(\mathrm{N}=130)\end{array}$} & \\
\hline & $\mathbf{n}$ & $\%$ & $\mathbf{n}$ & $\%$ & & $\mathbf{n}$ & $\%$ & $\mathbf{n}$ & $\%$ & \\
\hline 5-10 years & 65 & 40.1 & 6 & 35.3 & Referent & 15 & 31.9 & 54 & 41.5 & Referent \\
\hline $11-14$ years & 55 & 34.0 & 5 & 29.4 & $1.00(0.980)$ & 19 & 40.4 & 41 & 31.5 & $1.46(0.210)$ \\
\hline$\geq 15$ years & 42 & 25.9 & 6 & 35.3 & $0.96(0.490)$ & 13 & 27.7 & 35 & 26.9 & $1.25(0.500)$ \\
\hline \multicolumn{11}{|l|}{ Race/ethnicity } \\
\hline White non-Hispanic & 115 & 71.0 & 10 & 58.8 & Referent & 29 & 61.7 & 94 & 72.3 & Referent \\
\hline Black non-Hispanic & 9 & 5.6 & 0 & & --- & 2 & 4.3 & 7 & 5.4 & $0.94(0.930)$ \\
\hline Hispanic & 22 & 13.6 & 6 & 35.3 & $0.86(0.120)$ & 8 & 17.0 & 20 & 15.4 & $1.21(0.570)$ \\
\hline Other & 6 & 3.7 & 1 & 5.9 & $0.93(0.650)$ & 3 & 6.4 & 4 & 3.1 & $1.82(0.200)$ \\
\hline Unknown & 10 & 6.2 & 0 & & ---- & 5 & 10.6 & 5 & 3.9 & $2.12(0.030)$ \\
\hline \multicolumn{11}{|l|}{ State } \\
\hline $\mathrm{AZ}$ & 36 & 22.2 & 7 & 41.2 & Referent & 13 & 27.7 & 29 & 22.3 & Referent \\
\hline $\mathrm{CO}$ & 33 & 20.4 & 1 & 5.9 & $1.16(0.040)$ & 9 & 19.2 & 25 & 19.2 & $0.86(0.670)$ \\
\hline GA & 36 & 22.2 & 4 & 23.5 & $1.08(0.400)$ & 12 & 25.5 & 27 & 20.8 & $0.99(0.990)$ \\
\hline IA & 30 & 18.5 & 2 & 11.8 & $1.12(0.160)$ & 6 & 12.8 & 26 & 20.0 & $0.61(0.250)$ \\
\hline Western NY & 27 & 16.7 & 3 & 17.7 & $1.08(0.430)$ & 7 & 14.9 & 23 & 17.7 & $0.75(0.480)$ \\
\hline \multicolumn{11}{|l|}{ Ambulation status } \\
\hline Non-ambulatory & 92 & 56.8 & 12 & 70.6 & Referent & 31 & 66.0 & 73 & 56.2 & Referent \\
\hline Ambulatory & 54 & 33.3 & 4 & 23.5 & $1.05(0.310)$ & 12 & 25.5 & 45 & 34.6 & $0.71(0.240)$ \\
\hline Don’t know & 16 & 9.9 & 1 & 5.9 & $1.06(0.380)$ & 4 & 8.51 & 12 & 9.2 & --- \\
\hline \multicolumn{11}{|l|}{ Occupational therapy } \\
\hline Not received & 47 & 29.0 & 3 & 17.7 & Referent & 10 & 21.3 & 40 & 30.8 & Referent \\
\hline Only at School & 67 & 41.4 & 7 & 41.2 & $0.96(0.470)$ & 20 & 42.6 & 54 & 41.5 & $1.35(0.380)$ \\
\hline
\end{tabular}




\begin{tabular}{|c|c|c|c|c|c|c|c|c|c|c|}
\hline School and MP/Home & 19 & 11.7 & 4 & 23.5 & $0.89(0.210)$ & 6 & 12.8 & 16 & 12.3 & $1.36(0.500)$ \\
\hline Only at MP/Home & 27 & 16.7 & 2 & 11.8 & $0.99(0.880)$ & 10 & 21.3 & 18 & 13.9 & $1.79(0.130)$ \\
\hline Missing & 2 & 1.2 & 1 & 5.9 & -- & 1 & 2.1 & 2 & 1.5 & -- \\
\hline \multicolumn{11}{|l|}{ Physical therapy } \\
\hline Not received & 20 & 12.4 & 1 & 5.9 & Referent & 6 & 12.8 & 15 & 11.5 & Referent \\
\hline Only at School & 47 & 29.0 & 9 & 52.9 & $0.88(0.100)$ & 20 & 42.6 & 36 & 27.7 & $1.25(0.570)$ \\
\hline School and MP/Home & 28 & 17.3 & 4 & 23.5 & $0.92(0.310)$ & 7 & 14.9 & 25 & 19.2 & $0.77(0.580)$ \\
\hline Only at MP/Home & 67 & 41.4 & 2 & 11.8 & $1.02(0.710)$ & 14 & 29.8 & 53 & 40.8 & $0.73(0.460)$ \\
\hline Missing & 0 & & 1 & 5.9 & --- & 0 & & 1 & 0.8 & --- \\
\hline \multicolumn{11}{|l|}{ Speech therapy } \\
\hline Not received & 71 & 43.8 & 4 & 23.5 & Referent & 10 & 21.3 & 65 & 50.0 & Referent \\
\hline Only at School & 70 & 43.3 & 8 & 47.1 & $0.95(0.260)$ & 29 & 61.7 & 48 & 36.9 & $2.82(0.002)$ \\
\hline School and MP/Home & 9 & 5.6 & 2 & 11.8 & $0.86(0.310)$ & 5 & 10.6 & 6 & 4.6 & $3.41(0.006)$ \\
\hline Only at MP/Home & 11 & 6.8 & 2 & 11.8 & $0.89(0.360)$ & 2 & 4.3 & 10 & 7.7 & $1.25(0.750)$ \\
\hline Missing & 1 & 0.6 & 1 & 5.9 & --- & 1 & 2.1 & 1 & 0.8 & --- \\
\hline
\end{tabular}

\section{Caregiver and \\ Household \\ Characteristics}

\section{Education level of}

caregiver

$\begin{array}{rrrrrcrrrrr}>12 \text { years } & 117 & 72.2 & 7 & 41.2 & \text { Referent } & 30 & 63.8 & 92 & 70.8 & \text { Referent } \\ \leq 12 \text { years } & 37 & 22.8 & 7 & 41.2 & 0.89(0.100) & 13 & 27.7 & 31 & 23.9 & 1.20(0.510) \\ \text { Missing } & 8 & 4.9 & 3 & 17.7 & --- & 4 & 8.5 & 7 & 5.4 & ---\end{array}$

Household income

\begin{tabular}{|c|c|c|c|c|c|c|c|c|c|c|}
\hline$<\$ 30,000$ & 51 & 31.5 & 8 & 47.1 & Referent & 17 & 36.2 & 42 & 32.3 & Referent \\
\hline$\$ 30,000-\$ 50,000$ & 21 & 13.5 & 3 & 17.7 & $1.01(0.900)$ & 8 & 17.0 & 16 & 12.3 & $1.16(0.680)$ \\
\hline$>\$ 50,0000$ & 83 & 51.2 & 6 & 35.3 & $1.08(0.200)$ & 20 & 42.6 & 67 & 51.5 & $0.80(0.430)$ \\
\hline Missing & 7 & 4.3 & 0 & & --- & 2 & 4.3 & 5 & 3.9 & --- \\
\hline
\end{tabular}

$*$ Two cases had Repeated Grade = "Do not know" and were excluded; ** Z statistic; DMD = Duchenne muscular dystrophy; MD STARnet = Muscular
Dystrophy Surveillance Tracking and Research Network; MP = medical practice; AZ = Arizona; CO = Colorado; GA = Georgia; IA = Iowa; NY = western New York State; PR = Prevalence Ratio 
Table 3

Crude prevalence ratio $(P R)$ estimates of the association between various study subject and primary caregiver characteristics and usage of school aid and resource room among DMD cases in the MD STARnet cohort

\begin{tabular}{|c|c|c|c|c|c|c|c|c|c|c|}
\hline \multirow{3}{*}{$\begin{array}{l}\text { Study Subject } \\
\text { Characteristics } \\
\text { Age groups }\end{array}$} & \multicolumn{4}{|c|}{ Instructional Assistant } & \multirow[t]{3}{*}{$* \mathbf{P R}(* * \mathbf{P}$ value $)$} & \multicolumn{4}{|c|}{ Resource Room Support } & \multirow[t]{3}{*}{ *PR (**P value) } \\
\hline & \multicolumn{2}{|c|}{$\begin{array}{c}\text { Has an } \\
\text { assistant } \\
(\mathrm{N}=106)\end{array}$} & \multicolumn{2}{|c|}{$\begin{array}{c}\text { Does not have an } \\
\text { assistant } \\
(\mathrm{N}=72)\end{array}$} & & \multicolumn{2}{|c|}{$\begin{array}{l}\text { Receives } \\
\text { support } \\
(\mathrm{N}=105) \\
\end{array}$} & \multicolumn{2}{|c|}{$\begin{array}{l}\text { Does not } \\
\text { receive support } \\
(\mathrm{N}=73)\end{array}$} & \\
\hline & $\mathbf{n}$ & $\%$ & $\mathbf{n}$ & $\%$ & & $\mathbf{n}$ & $\%$ & $\mathbf{n}$ & $\%$ & \\
\hline $5-10$ years & 30 & 28.3 & 41 & 56.9 & Referent & 46 & 43.8 & 24 & 32.9 & Referent \\
\hline $11-14$ years & 42 & 39.6 & 17 & 23.6 & $1.68(0.001)$ & 37 & 35.2 & 23 & 31.5 & $0.94(0.630)$ \\
\hline$\geq 15$ years & 34 & 32.1 & 14 & 19.4 & $1.67(0.002)$ & 22 & 21.0 & 26 & 35.6 & $0.70(0.040)$ \\
\hline \multicolumn{11}{|l|}{ Race/ethnicity } \\
\hline White non-Hispanic & 75 & 70.8 & 50 & 69.4 & Referent & 72 & 68.6 & 53 & 72.6 & Referent \\
\hline Black non-Hispanic & 6 & 5.7 & 2 & 2.8 & $1.25(0.300)$ & 5 & 4.8 & 4 & 5.5 & $0.96(0.910)$ \\
\hline Hispanic & 15 & 14.2 & 13 & 18.1 & $0.89(0.550)$ & 17 & 16.2 & 10 & 13.7 & $1.09(0.590)$ \\
\hline Other & 4 & 3.8 & 3 & 4.2 & $0.95(0.880)$ & 6 & 5.7 & 1 & 1.4 & $1.48(0.020)$ \\
\hline Unknown & 6 & 5.7 & 4 & 5.6 & $1.00(1.000)$ & 5 & 4.8 & 5 & 6.9 & $0.88(0.660)$ \\
\hline \multicolumn{11}{|l|}{ State } \\
\hline $\mathrm{AZ}$ & 27 & 25.5 & 16 & 22.2 & Referent & 27 & 25.7 & 16 & 21.9 & Referent \\
\hline $\mathrm{CO}$ & 22 & 20.8 & 12 & 16.7 & $1.03(0.860)$ & 20 & 19.1 & 14 & 19.2 & $0.94(0.720)$ \\
\hline GA & 17 & 16.0 & 22 & 30.6 & $0.69(0.100)$ & 23 & 21.9 & 16 & 21.9 & $0.94(0.720)$ \\
\hline IA & 21 & 19.8 & 11 & 15.3 & $1.05(0.800)$ & 17 & 16.2 & 15 & 20.6 & $0.85(0.410)$ \\
\hline Western NY & 19 & 17.9 & 11 & 15.3 & $1.01(0.960)$ & 18 & 17.1 & 12 & 16.4 & $0.96(0.810)$ \\
\hline \multicolumn{11}{|l|}{ Ambulation status } \\
\hline Non-ambulatory & 75 & 70.8 & 28 & 38.9 & Referent & 64 & 61.0 & 39 & 53.4 & Referent \\
\hline Ambulatory & 25 & 23.6 & 33 & 45.8 & $0.59(0.001)$ & 33 & 31.4 & 25 & 34.3 & $0.92(0.520)$ \\
\hline Don't know & 6 & 5.7 & 11 & 15.3 & -- & 8 & 7.6 & 9 & 12.3 & -- \\
\hline \multicolumn{11}{|l|}{ Occupational therapy } \\
\hline Not received & 21 & 19.8 & 29 & 40.3 & Referent & 24 & 22.9 & 25 & 34.3 & Referent \\
\hline Only at School & 50 & 47.2 & 24 & 33.3 & $1.61(0.010)$ & 46 & 43.8 & 28 & 38.4 & $1.27(0.170)$ \\
\hline
\end{tabular}




\begin{tabular}{|c|c|c|c|c|c|c|c|c|c|c|}
\hline School and MP/Home & 15 & 14.2 & 7 & 9.7 & $1.62(0.030)$ & 19 & 18.1 & 4 & 5.5 & $1.69(0.003)$ \\
\hline Only at MP/Home & 17 & 16.0 & 12 & 16.7 & $1.40(0.140)$ & 15 & 14.3 & 14 & 19.2 & $1.06(0.810)$ \\
\hline Missing & 3 & 2.8 & 0 & & -- & 1 & 0.9 & 2 & 2.7 & --- \\
\hline \multicolumn{11}{|l|}{ Physical therapy } \\
\hline Not received & 12 & 11.3 & 9 & 12.5 & Referent & 12 & 11.4 & 9 & 12.3 & Referent \\
\hline Only at School & 37 & 34.9 & 19 & 26.4 & $1.16(0.490)$ & 33 & 31.4 & 22 & 30.1 & $1.05(0.820)$ \\
\hline School and MP/Home & 20 & 18.9 & 12 & 16.7 & $1.09(0.700)$ & 23 & 21.9 & 9 & 12.3 & $1.26(0.290)$ \\
\hline Only at MP/Home & 36 & 34.0 & 32 & 44.4 & $0.93(0.730)$ & 36 & 34.3 & 33 & 45.2 & $0.91(0.680)$ \\
\hline Missing & 1 & 0.9 & 0 & & --- & 1 & 0.9 & 0 & & --- \\
\hline \multicolumn{11}{|l|}{ Speech therapy } \\
\hline Not received & 35 & 33.0 & 40 & 55.6 & Referent & 32 & 30.5 & 43 & 58.9 & Referent \\
\hline Only at School & 54 & 50.9 & 24 & 33.3 & $1.48(0.006)$ & 56 & 53.3 & 22 & 30.1 & $1.68(0.001)$ \\
\hline School and MP/Home & 8 & 7.6 & 2 & 2.8 & $1.71(0.007)$ & 9 & 8.6 & 2 & 2.7 & $1.92(0.001)$ \\
\hline Only at MP/Home & 9 & 8.5 & 4 & 5.6 & $1.48(0.080)$ & 7 & 6.7 & 6 & 8.2 & $1.26(0.420)$ \\
\hline Missing & 0 & & 2 & 2.8 & --- & 1 & 0.9 & 0 & & --- \\
\hline
\end{tabular}

\section{Caregiver and}

\section{Household}

\section{Characteristics}

\section{Education level of} caregiver

\begin{tabular}{|c|c|c|c|c|c|c|c|c|c|c|}
\hline$>12$ years & 68 & 64.2 & 55 & 76.4 & Referent & 66 & 62.9 & 58 & 79.5 & Referent \\
\hline$\leq 12$ years & 30 & 28.3 & 14 & 19.4 & $1.23(0.110)$ & 30 & 28.6 & 13 & 17.8 & $1.31(0.040)$ \\
\hline Missing & 8 & 7.6 & 3 & 4.2 & -- & 9 & 8.6 & 2 & 2.7 & -- \\
\hline income & & & & & & & & & & \\
\hline$<\$ 30,000$ & 35 & 33.0 & 23 & 31.9 & Referent & 38 & 36.2 & 20 & 27.4 & Referent \\
\hline$, 000-\$ 50,000$ & 17 & 16.0 & 7 & 9.7 & $1.17(0.340)$ & 13 & 12.4 & 11 & 15.1 & $0.83(0.370)$ \\
\hline$>\$ 50,0000$ & 50 & 47.2 & 39 & 54.2 & $0.93(0.610)$ & 50 & 47.6 & 39 & 53.4 & $0.86(0.250)$ \\
\hline Missing & 4 & 3.8 & 3 & 4.2 & --- & 4 & 3.8 & 3 & 4.1 & --- \\
\hline
\end{tabular}

Household income

*One case had Instructional Assistant= "Do not know" and was excluded; *One case had Resource Help = "Do not know" and was excluded; ** Z statistic; DMD = Duchenne muscular dystrophy; MD STARnet = Muscular Dystrophy Surveillance Tracking and Research Network; MP = medical practice; AZ = Arizona; $\mathrm{CO}=$ Colorado; $\mathrm{GA}=$ Georgia; $\mathrm{IA}=$ Iowa; $\mathrm{NY}=$ western New York State; $\mathrm{PR}=$ Prevalence Ratio 
Table 4

Adjusted prevalence ratio $(a P R)$ of the association between various study subject and primary caregiver characteristics and public school enrollment, grade repetition, usage of school aid, and resource room help among DMD cases in the MD STARnet cohort

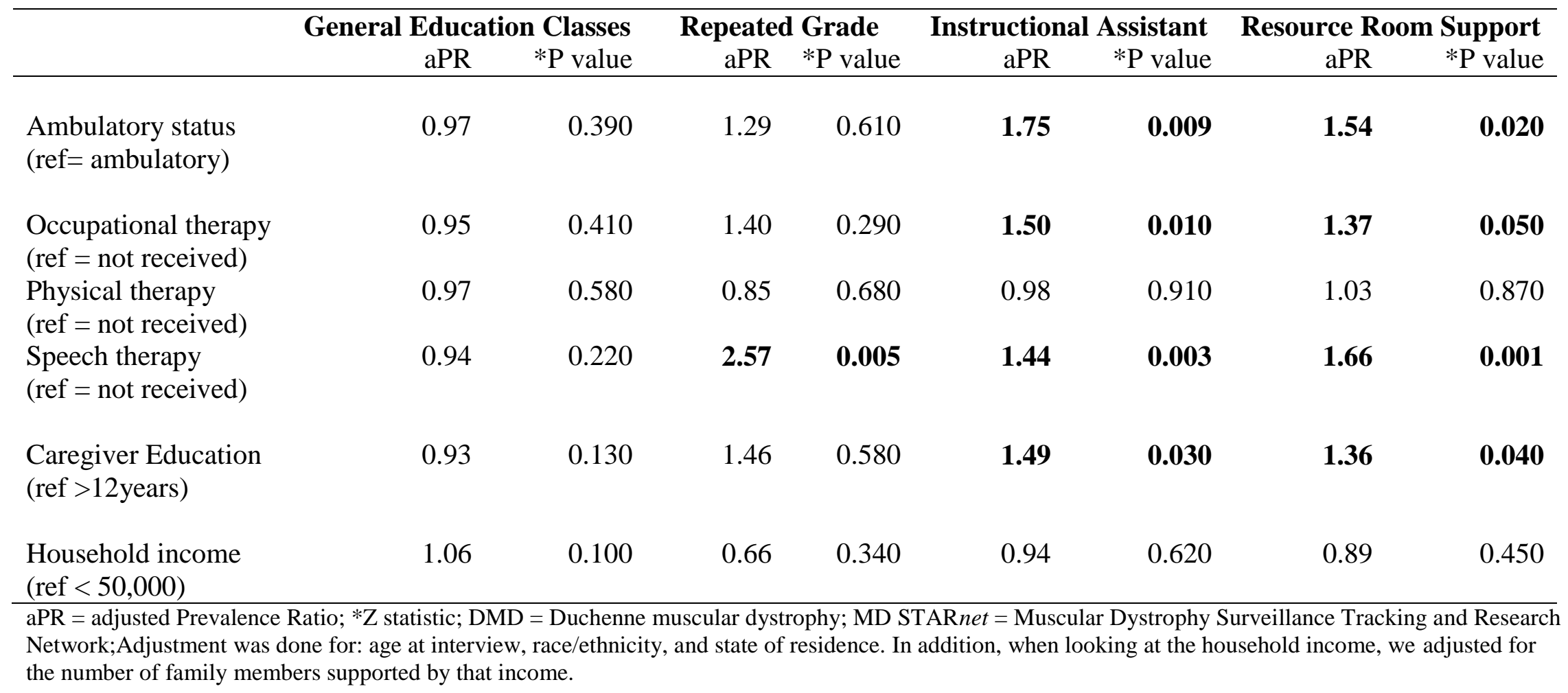


Table 5

Distribution of DBMD case and primary caregiver characteristics by participation in general education classes, MD STARnet cohort

\begin{tabular}{|c|c|c|c|}
\hline $\begin{array}{l}\text { Study Subject and } \\
\text { Caregiver Characteristics }\end{array}$ & $\begin{array}{l}\text { Alive and Reported No General } \\
\text { Education Classes }(n=93)\end{array}$ & $\begin{array}{l}\text { Attended General Education Classes } \\
\qquad(n=210)\end{array}$ & *P value \\
\hline Age groups & $n$ & $n$ & \\
\hline $5-10$ years & 8.6 & 38.1 & $<0.001$ \\
\hline $11-14$ years & 1.1 & 33.8 & \\
\hline$\geq 15$ years & 90.3 & 28.1 & \\
\hline \multicolumn{4}{|l|}{ Race/ethnicity } \\
\hline White non-Hispanic & 68.8 & 68.6 & 0.290 \\
\hline Black non-Hispanic & 4.3 & 5.7 & \\
\hline Hispanic & 16.1 & 16.2 & \\
\hline Other & 0.0 & 3.3 & \\
\hline Unknown & 10.8 & 6.2 & \\
\hline \multicolumn{4}{|l|}{ State } \\
\hline AZ & 24.7 & 22.9 & 0.790 \\
\hline $\mathrm{CO}$ & 17.2 & 18.6 & \\
\hline GA & 25.8 & 22.4 & \\
\hline IA & 20.4 & 19.0 & \\
\hline Western NY & 11.8 & 17.1 & \\
\hline \multicolumn{4}{|l|}{ Education level of caregiver } \\
\hline$>12$ years & 50.5 & 67.1 & 0.030 \\
\hline$\leq 12$ years & 36.6 & 26.2 & \\
\hline Missing & 12.9 & 6.6 & \\
\hline \multicolumn{4}{|l|}{ Household income } \\
\hline$<\$ 30,000$ & 32.3 & 31.4 & 0.170 \\
\hline$\$ 30,000-\$ 50,000$ & 17.2 & 12.4 & \\
\hline$>\$ 50,0000$ & 36.6 & 52.4 & \\
\hline Missing & 16 & 8 & \\
\hline
\end{tabular}


transition between classes. Physical assistance for transfers and physical tasks is also recommended when necessary (EndDuchenne.org - Leading the fight to end Duchenne muscular dystrophy - Parent Project Muscular Dystrophy, n.d.).

In our study, about one-half of males with DMD were reported as receiving OT or PT at school. Zebracki and Drotar (2008) and Pandya et al. (2015) also reported high prevalence of recipients of occupational and physical therapies, however their study did not differentiate between therapies received at school or other facilities. Interestingly, in a study on variation in educational services receipt among U.S. children with developmental conditions (autism spectrum disorder, developmental delay, and intellectual disability), Lindly, Sinche, and Zuckerman (2015) observed that children with intellectual disability were more likely to have received one or more school-based therapies (OT, PT, social skills training, ST, or language therapy) than those with autism and developmental delay, while children with developmental delay were less likely than the rest of the sample to have received one or more school-based therapies. While we did not measure the level of intellectual delay/disability in our study sample, we do know that 20-50\% of boys with DMD are diagnosed with cognitive deficits (Wicksell et al., 2007). Evaluating cognitive deficits and the receipt of therapies for cognitive disorders was beyond the scope of our study. Therefore, future studies should evaluate whether all students with cognitive disorders due to DMD and who need therapy, are receiving it at school, and examine the characteristics associated with having or not having their therapy needs identified in a timely manner.

In the current study, $57 \%$ of males with DMD were reported as receiving ST. In a study by Cyrulnik et al. (2007) on delayed developmental language milestones in children with DMD, speech delay was observed in $38 \%$ of boys with DMD. One explanation for the high prevalence of ST use in our study is that, although receiving ST could be an indicator of speech delay, the interview used in the current study was not designed to evaluate any language milestones. In our study, males with DMD who received ST had a statistically increased prevalence for grade repetition, instructional assistant use, and resource room use when compared to non-recipients.

Higher rates of speech and language deficits among children with DMD are well documented. Deficiency in phonological processing combined with problems in short-term memory could result in learning disability (Bushby et al., 2010). Hinton et al. (2004) recommended educational interventions such as breaking detailed verbal instructions into smaller segments, repeating verbal information, and phonological awareness training. The survey used in our study did not distinguish among the conditions for which ST was provided.

Lastly, the multivariable model showed that males with DMD whose caregivers had less than 12 years of education were significantly more likely to use an instructional assistant and resource room support than those whose caregivers had at least 12 years of education. No literature to date has explored the relationship between the education level of caregivers of children with DMD and the use of school-based services. 


\section{Males with BMD}

Out of 31 males with BMD in our sample, 97\% reported participation in general education classes, a prevalence similar to that observed by Magliano et al. (2014). In the current study, $19 \%$ reported grade repetition, and $29 \%$ and $35.5 \%$ respectively reported instructional assistant and resource room use. In addition, between one-third and one-half of males with BMD reported receiving PT, OT, or ST in school.

\section{Strengths}

This is the first study to date that describes school experiences and the accommodations and services that males with DMD or BMD receive in school. MD STARnet is a comprehensive population-based cohort identified through neuromuscular clinics, hospitals and hospital discharge databases, private physicians, service sites for children with special care needs, and birth defects surveillance programs in six states. Definition/classification of DBMD was reviewed by experienced clinicians and diagnosis was confirmed by laboratory data and/or family pedigree. Health data were collected using medical records and therefore were not subject to recall bias.

\section{Limitations}

The males identified through the MD STARnet cohort may not be representative of the entire DBMD population in the U.S., since the participant states were not randomly selected. Additionally, a small number of males with DBMD may not have interacted with the specialty clinics and, therefore, those cases were not captured. The survey response rate of 53\% may limit the generalizability of our findings to the entire MD STARnet population. However, we compared selected study subject and parental characteristics between eligible MD STARnet families and interviewed families, and we observed similar distribution of case status, child year of birth, vital status, maternal and paternal age at interview, race/ethnicity, and maternal and paternal education level. Therefore, the potential selection bias caused by the relatively low response rate is minimal.

The survey data did not differentiate between types of schools (e.g., public, private, or parochial) or the location of schools (rural versus urban), characteristics that may impact the resources available to meet the needs of children with disabilities. The survey did not collect information related to speech, language, learning, cognitive, and behavioral characteristics that may impact the school experience and learning/school success. Also, although many of the males with DMD and BMD were enrolled in general education classes, the survey did not collect information on the amount of time they spent in those classes. Regarding the various types of therapy received at school, the interview did not determine whether these males qualified for any of these therapies. Children may qualify for, but choose not to receive, therapies at school. 


\section{Implications for Practice and Future Research}

Schools can use these data to plan and allocate their resources to ensure that classroom accommodations and adaptive equipment that can help males with DBMD are being provided. Teachers and school-based therapists can use these data to ensure they understand the progress of DBMD and its impact on classroom activities. Parents can use these results to advocate for resources that boys with DBMD may need in order to thrive in the school setting. Policymakers can use these results to ensure that laws pertaining to special education appropriately accommodate the needs of this medically and cognitively complex population. Since our study did not examine compliance, future studies should also survey schools to identify compliance with current laws regarding special needs accommodations, barriers to identification of educational needs in children with progressive physical disabilities as well as potential cognitive deficits, and provision of services to boys with DBMD. In addition, our study did not examine the quality of the services received by boys with DBMD. Future studies should more extensively survey families of boys with DBMD to evaluate the quality of educational assistance at home and at school. Combined, these data can serve to provide adequate assistance in school and improve the academic achievement of boys with DBMD.

\section{References}

Bushby, K., Finkel, R., Birnkrant, D. J., Case, L. E., Clemens, P. R., Cripe, L., ... Constantin, C. (2010). Diagnosis and management of Duchenne muscular dystrophy, part 1: Diagnosis and pharmacological and psychosocial management. The Lancet Neurology, 9(1), 77-93. http://dx.doi.org/10.1016/s1474-4422(09)70271-6

Ciafaloni, E., Chinnery, P. F., \& Griggs, R. C. (2014). Evaluation and treatment of myopathies. New York, NY: Oxford University Press.

Cyrulnik, S. E., Fee, R. J., De Vivo, D. C., Goldstein, E., \& Hinton, V. J. (2007). Delayed developmental language milestones in children with Duchenne's muscular dystrophy. The Journal of Pediatrics, 150(5), 474-478. http://dx.doi.org/10.1016/j.jpeds.2006.12.045

EndDuchenne.org - Leading the fight to end Duchenne muscular dystrophy - Parent Project Muscular Dystrophy. (n.d.). Retrieved from http://www.parentprojectmd.org/

Heller, K. W., Mezei, P. J., \& Avant, M. J. T. (2008). Meeting the assistive technology needs of students with Duchenne muscular dystrophy. Journal of Special Education Technology, 23(4), 15-30.

Hinton, V. J., De Vivo, D. C., Nereo, N. E., Goldstein, E., \& Stern, Y. (2000). Poor verbal working memory across intellectual level in boys with Duchenne dystrophy. Neurology, 54(11), 2127-2132. http://dx.doi.org/10.1212/wnl.54.11.2127 
Hinton, V. J., De Vivo, D. C., Fee, R., Goldstein, E., \& Stern, Y. (2004). Investigation of poor academic achievement in children with Duchenne muscular dystrophy. Learning Disabilities Research and Practice, 19(3), 146-154. http://dx.doi.org/10.1111/j.1540$\underline{\text { 5826.2004.00098.x }}$

Kornberg, A., \& Yiu, E. (2008). Duchenne muscular dystrophy. Neurology India, 56(3), 236. http://dx.doi.org/10.4103/0028-3886.43441

Lindly, O. J., Sinche, B. K., \& Zuckerman, K. E. (2015). Variation in educational services receipt among US children with developmental conditions. Academic Pediatrics, 15(5), 534-543. http://dx.doi.org/10.1016/j.acap.2015.04.001

Lopez-Hernandez, L. B., Gomez-Diaz, B., Escobar-Cedillo, R. E., Gama-Moreno, O., CamachoMolina, A., Soto-Valdes, D. M., \& Coral-Vasquez, R. M. (2014). Duchenne muscular dystrophy in a developing country: Challenges in management and genetic counseling. Genetic Counseling, 25(2), 129-141.

Magliano, L., D'Angelo, M. G., Vita, G., Pane, M., D'Amico, A., Balottin, U., \& Scutifero, M. (2014). Psychological and practical difficulties among parents and healthy siblings of children with Duchenne vs. Becker muscular dystrophy: An Italian comparative study. Acta Myologica, 33(3), 136-143.

Mathews, K. D., Cunniff, C., Kantamneni, J. R., Ciafaloni, E., Miller, T., Matthews, D., ... Romitti, P. A. (2010). Muscular Dystrophy Surveillance Tracking and Research Network (MD STARnet): Case definition in surveillance for childhood-onset Duchenne/Becker muscular dystrophy. Journal of Child Neurology, 25(9), 1098-1102. http://dx.doi.org/10.1177/0883073810371001

Miller, L. A., Romitti, P. A., Cunniff, C., Druschel, C., Mathews, K. D., Meaney, F. J., ... Kenneson, A. (2006). The muscular Dystrophy Surveillance Tracking and Research Network (MD STARnet): Surveillance methodology. Birth Defect Res A, 76(11), 793797. http://dx.doi.org/10.1002/bdra.20279

Muscular Dystrophy Association. (n.d.). Retrieved from https://www.mda.org

Pandya, S. K., Campbell, K. A., Andrews, J. G., Meaney, F. J., \& Ciafaloni, E. (2015). Health services received by individuals with Duchenne/Becker muscular dystrophy. Muscle \& Nerve, 53(2), 191-197. http://dx.doi.org/10.1002/mus.24727

Petersen, M. R., \& Deddens, J. A. (2008). A comparison of two methods for estimating prevalence ratios. BioMed Central Medical Research Methodology, 8(1). http://dx.doi.org/10.1186/1471-2288-8-9 
Response Rates - An Overview - AAPOR. (n.d.). Retrieved from http://www.aapor.org/Education-Resources/For-Researchers/Poll-SurveyFAQ/Response-Rates-An-Overview.aspx

Romitti, P. A., Zhu, Y., Puzhankara, S., James, K. A., Nabukera, S. K., Zamba, G. K., ... Bolen, J. (2015). Prevalence of Duchenne and Becker muscular dystrophies in the United States. Pediatrics, 135(3), 513-521. http://dx.doi.org/10.1542/peds.2014-2044

Wicksell, R. K., Kihlgren, M., Melin, L., \& Eeg-Olofsson, O. (2007). Specific cognitive deficits are common in children with Duchenne muscular dystrophy. Developmental Medicine \& Child Neurology, 46(3), 154-159. http://dx.doi.org/10.1111/j.1469-8749.2004.tb00466.x

Worden, D. K., \& Vignos, P. J. (1962). Intellectual function in childhood progressive muscular dystrophy. Pediatrics, 29, 968-997.

Yiu, E. M., \& Kornberg, A. J. (2015). Duchenne muscular dystrophy. Journal of Paediatrics and Child Health, 51(8), 759-764. http://dx.doi.org/10.1111/jpc.12868

Young, H. K., Barton, B. A., Waisbren, S., Portales Dale, L., Ryan, M. M., Webster, R. I., \& North, K. N. (2007). Cognitive and psychological profile of males with Becker muscular dystrophy. Journal of Child Neurology, 23(2), 155-162. http://dx.doi.org/10.1177/0883073807307975

Zebracki, K., \& Drotar, D. (2008). Pain and activity limitations in children with Duchenne or Becker muscular dystrophy. Developmental Medicine \& Child Neurology, 50(7), 546-552. http://dx.doi.org/10.1111/j.1469-8749.2008.03005.x

Author's Note: This publication was supported by the Cooperative Agreement numbers, DD000187, DD000189, DD000190, DD000191, and DD001116 funded by the Centers for Disease Control and Prevention. Its contents are solely the responsibility of the authors and do not necessarily represent the official views of the Centers for Diseases Control and Prevention or the Department of Health and Human Services. We are grateful to the families who participated in this study. We thank study coordinators, interviewers, and data managers for assistance with data collection and management.

Correspondence concerning this article should be addressed to: Aida Soim, PhD, MD, Center for Environmental Health, Bureau of Environmental and Occupational Epidemiology, Birth Defects Registry and Surveillance Section, Empire State Plaza, Corning Tower, Room 1203, Albany, NY 12237, telephone: (518) 402-7950, fax: (518) 402-7959, e-mail: aida.soim@ health.ny.gov 